\title{
Amundsen versus Scott: are growth paths related to firm performance?
}

\author{
Alex Coad (D) Sven-Olov Daunfeldt • \\ Daniel Halvarsson
}

Accepted: 12 August 2021

(C) The Author(s), under exclusive licence to Springer Science+Business Media, LLC, part of Springer Nature 2021

\begin{abstract}
In the race to the South Pole, Roald Amundsen's expedition covered an equal distance each day, irrespective of weather conditions, while Scott's pace was erratic. Amundsen won the race and returned without loss of life, while Scott and his men died. In the context of firm growth, the Amundsen hypothesis suggests that smoother growth paths are associated with better performance in subsequent periods. We develop a new method to investigate how firms' sales growth deviates from their long-run average growth path. Our baseline results suggest that growth path volatility is associated with higher growth of sales and profits, but also with higher exit rates. However, this result is driven by firms with negative growth rates. For positive-growth firms,
\end{abstract}

Supplementary Information The online version contains supplementary material available at https://doi. org/10.1007/s11187-021-00552-y.

A. Coad ( $\square)$

Waseda Business School, Tokyo, Japan

e-mail: alex.coad@waseda.jp

S.-O. Daunfeldt

Institute of Retail Economics, Stockholm, Sweden

e-mail: sven-olov.daunfeldt@huiresearch.se

S.-O. Daunfeldt

Dalarna University, Falun, Sweden

D. Halvarsson

The Ratio Institute, Stockholm, Sweden

e-mail: daniel.halvarsson@ ratio.se volatility is negatively associated with both sales growth and survival, providing nuanced support for the Amundsen hypothesis.

Plain English Summary In the race to the South Pole, Roald Amundsen and Robert Falcon Scott adopted different strategies that resulted in victory for Amundsen and death for Scott. Amundsen's approach was to consistently pace his team (to cover a fixed and equal distance each day), while Scott sought to cover as much distance as possible each day. In the context of firm growth, this relates to the tradeoff between steady growth (low volatility in growth rates) and growing as fast as possible in each period (potentially leading to high volatility in growth rates). We develop a new set of indicators for quantifying firms' growth paths, observing that growth path volatility in general is associated with higher growth of sales and profits, but also with higher death rates. This result is driven by firms with negative sales growth, however. Like Amundsen, it seems beneficial for firms with positive sales growth to pace themselves to increase their subsequent growth and likelihood of survival.

Keywords Firm dynamics · Sales growth · Firm exit · Growth paths $\cdot$ Scale-up $\cdot$ Post-entry growth

JEL classifications $\quad$ D22 $\cdot$ L25 $\cdot$ L26 


\section{Introduction}

Between December 1911 and January 1912, Roald Amundsen and Robert Falcon Scott reached the South Pole within a month of each other. Amundsen's expedition reached the pole first and returned without loss of life, while Scott and his four companions died on the return journey. Amundsen had planned his expedition carefully and irrespective of the weather conditions he sought to cover a fixed and equal distance each day, taking proper rests. Scott sought to cover as much distance as possible each day, and his journey was more erratic. ${ }^{1}$

Collins and Hansen (2011) draw parallels with the Amundsen-Scott case and stipulate in their bestselling management book Great by choice that firms' growth processes can predict which firms are going to be successful in the long run. ${ }^{2}$ Hence, firms with more stable growth paths will have better long-run performance than comparable firms with more volatile growth paths. We call this the Amundsen hypothesis. The idea that growth paths might tell us something about firms' future success is intriguing given the interest of entrepreneurship scholars in growth processes (see, e.g. Delmar et al., 2003; McKelvie \& Wiklund, 2010).

However, theory gives us no clear answer on whether smooth growth paths are better than more erratic growth paths. This seems important, because an understanding of how growth path volatility relates to performance can help avoid situations where firms engage in excessively erratic growth that threatens their survival or where over-cautious firms unnecessarily forego valuable opportunities.

On the one hand, volatility has a number of disadvantages. Volatility makes it harder for managers to plan ahead because it gets more difficult to predict future demand (Bloom, 2014; Bo, 2001) ${ }^{3}$ and adds

\footnotetext{
1 Amundsen and Scott's preparations and race to the South Pole is excellently covered in Roland Huntford's novel The Last Place on Earth: Scott and Amundsen's Race to the South Pole (Huntford, 1999).

2 While we concur that the Amundsen-Scott case is an interesting metaphor for starting discussions about firm growth paths, of course, we do not claim the metaphor is perfect.

${ }^{3}$ It is also possible that more volatile growth paths are signs that the firm is governed by managers that are less able to plan ahead, i.e., that volatility rather is a consequence of bad planning.
}

psychological stress that can have negative effects on managerial decisions (Stephan, 2018). Volatility also raises the risk premium and thereby lowers the valuation of the firm, making it more costly to borrow money from external investors (Bloom, 2014). In addition, it raises average costs because adjustment costs increase when the firm needs to adapt its scale of operations more frequently (Hamermesh \& Pfann, 1996). Volatility can also introduce enduring weaknesses inside the organization, e.g. poor choices of new hires that remain inside the firm and shape the firm's subsequent evolution (Coad et al., 2014).

On the other hand, volatility of growth rates may be an inevitable characteristic of the growth process. firm growth is an inherently lumpy process (Doms \& Dunne, 1998) and growth-oriented firms might be characterized by more volatile growth paths than firms with lower growth ambitions (Wiklund \& Shepherd, 2011), especially if they attempt to grow out of their existing niches and markets to pursue riskier opportunities further afield (Cowling \& Nadeem, 2020; Cowling et al., 2019). More volatile growth can also be beneficial due to first-mover advantages (Lieberman \& Montgomery, 1988). Firms that make more discretionary decisions to get into pole position can, for example, generate sustainable cost advantages and create barriers to entry for competitors due to learning-based efficiency gains (Spence, 1981). Firms that are characterized by more volatile growth paths can leap forward at critical junctures to develop patents to protect their innovations and discourage rivals from entering the race (Gilbert \& Newbery, 1982), and gain advantages over other firms by acquiring scarce assets such as physical resources and human capital (Carow et al., 2004). Volatile growth to gain first-mover advantages also means that firms can insulate their customer base by setting up "switching costs" for customers that move, and these switching costs would require competitors to invest more in order to attract their customers (Wernerfelt, 1986, 1988). However, efforts to seize first-mover advantages may themselves contribute to volatility, if a "J-curve" effect brings about short-term disruption from large initial investments before ultimately leading to longer-term positive impacts (Brynjolfsson et al., 2021).

We contribute to the literature by developing a new methodology for quantifying growth paths, and by investigating a novel hypothesis regarding how 
growth volatility relates to performance. We build on recent calls to focus not just on how much firms grow (e.g. the standard approach where firm growth is the dependent variable, and a long list of potential determinants are included as explanatory variables), but instead on how firms grow (McKelvie \& Wiklund, 2010). Our study thus contributes to a small but growing literature that investigates the growth paths taken by growing firms.

The pioneering paper by Delmar et al. (2003) sorted firms into seven categories on the basis of their employment, sales, and acquisition activity. These categories were super absolute growers (13.5\%); steady sales growers (12.8\%); acquisition growers (10\%); super relative growers (16.3\%); erratic oneshot growers (16.7\%); employment growers (16.0\%); and steady overall growers (14.8\%). Other scholars have taken similar approaches to categorize firms into 3-6 classes according to their growth performance (Acs et al., 2008; Cowling \& Liu, 2011; McMahon, 2001). For example, McMahon (2001) applies cluster analysis on the variables age, size, and growth rate, to classify firms as being low growth (70\%), moderate growth $(25 \%)$, or high growth $(5 \%)$. A different stream of literature has focused on growth paths in terms of sequences of above- or below-median growth over consecutive years (Coad et al., 2013, 2015: Derbyshire \& Garnsey, 2014; see also Brenner \& Schimke, 2015). We go beyond this stream of literature by developing a more sophisticated set of quantitative measures of growth path volatility.

More closely related to our work, Elizabeth Garnsey and colleagues take a graphical approach to allocating firms into growth path categories (Garnsey \& Heffernan, 2005; Garnsey et al., 2006). However, beyond showing some interesting graphical categories, they do not develop or apply any indicators that could quantify the volatility of firm growth paths; neither do they undertake any quantitative analysis of the consequences of growth paths on firm performance. We contribute to the literature by developing and applying a series of indicators for quantifying the volatility of firm growth paths. We argue that such quantitative indicators of growth paths are important additions to the literature for undertaking a rigorous analysis of growth paths and their consequences, for investigating effect sizes and for knowledge cumulativeness by facilitating comparisons across samples.
Our indicator of growth path volatility measures how sales growth deviates from firms' long-run average growth path and captures several desirable statistical properties, e.g. taking value zero in cases where growth is equal in every period, increasing monotonically with respect to inequality of growth rates across periods, and is invariant to whether a firm 'overshoots' or 'under-shoots' with respect to its overall growth path. The indicator also controls for the number of times that the yearly sales growth crosses over the long-run average growth path and can be used to classify firms into different growth types based on how they grow in relation to their average long-run growth path. We use this classification to test if venture performance is related to growth paths around the long-run average. As far as we know, no previous study has been able to provide such a test.

The Amundsen hypothesis suggests that smoother growth paths are associated with higher growth and better performance in subsequent periods. We test the Amundsen hypothesis using a dataset that includes the full population of limited liability firms (with at least one employee) in Sweden during the period 1998-2009, investigating the effects of growth path variability on sales growth, profit growth, and firm exit in the coming 3-year period.

Overall, we find that growth path volatility is positively associated with growth of sales and profits, but also positively associated with firm exit. However, the positive effects of volatility on growth are mainly driven by the lower end of the growth rates distribution, suggesting that volatility slows down the decline of firms with negative growth rates. For fast-growing firms, growth path volatility is negatively associated with sales growth and negatively associated with exit probability in the coming 3-year period, thus providing support for the Amundsen hypothesis in the context of fast-growing firms. However, for the fastest growing firms, erratic growth paths are positively associated with profit growth.

We also find a more complex relationship between firms' growth paths and their performance when classifying firms into eight different growth types. Firms that have more years with sales growth above rather than below their long-run average growth path, holding their growth volatility constant, have higher sales growth in the coming three-year period. We also find similar results for profit growth, while higher growth 
path volatility is associated with higher risk of exiting the market for all growth types. Our research thus highlights the importance of not only investigating growth volatility and how much firms grow, but also how firms grow around their average growth path.

The rest of the paper is organized as follows. The next section presents our theoretical background and our hypotheses. Section 3 describes the dataset and the empirical methodology, while our results are presented in Section 4. Finally, we conclude and discuss the implications of our findings in Section 5.

\section{Theory and hypotheses}

Firm growth is an inherently lumpy process. As a firm grows, it introduces new inputs and processes, new divisions of labor, and new hierarchical levels. One source of lumpiness is that the inputs are indivisible. Firms cannot grow by adding half of a machine, or a quarter of a production plant. This means that firm growth sometimes requires leaps. In their analysis of US manufacturing plants, Doms and Dunne (1998, p. 417) report a considerable concentration of investment into short periods: "on average, half of a plant's total investment over the 1973-1988 period was performed in just three years." Firms often find themselves at critical junctures, whereby the addition of one resource can have cascading effects in terms of increased requirements on other resources in the organization. For example, adding a production worker increases the workload of supervisors. Furthermore, growth via the addition of new resources changes the configuration of existing resources, thus opening up new opportunities and directions for the addition of new resources (Penrose, 1959). In the context of entrepreneurial ventures, adding a new employee to a small team opens up new possibilities of division of labor and hierarchical organization that may open up new opportunities for growth.

Another source of lumpiness is that scaling up changes the structure of organizations. In a metaphor to the structural change that accompanies the growth of organizations, Hannan and Freeman (1977) write that "a mouse could not possibly maintain the same proportion of body weight to skeletal structure while growing as big as a house. It would look neither like a mouse nor operate physiologically like a mouse" (Hannan and Freeman, 1977, p. 938). Growth therefore is not merely a linear accumulation but is interrupted by episodes of broad-based restructuring. Cruz et al. (2018) observe that the growth of successful firms involves a proactive eye towards the creation of new hierarchical layers.

The above discussion implies that the marginal costs of growth, in terms of increasing sales by one basic unit, are not constant, but depend upon the way that resources are organized within the firm (Coad \& Planck, 2012). In some cases, growth can quite easily build upon existing infrastructural capacity and organizational slack. In other cases, growth is more difficult because it requires investing simultaneously in various resources and complementary assets. As a result, achieving a fixed growth rate is easier in some years than in others.

In addition to the intrinsic lumpiness of growth, it sometimes pays to grow as fast as possible because of first mover advantages (Lieberman \& Montgomery, 1988). Growth in cumulative output, for example, can give rise to learning-based efficiency gains for first movers, generating sustainable cost advantages and barriers to entry (Spence, 1981) and thus reward firms that move first. First mover advantages also arise if technology can be protected using patents or if maintained as trade secrets. This has been formalized in the theoretical economics literature in the form of $R \& D$ or patent races where advantages are often enjoyed by the first-mover firm. Gilbert and Newbery (1982) were the first to develop a model of preemptive patenting, in which a firm with an early head start in research exploits its lead to deter rivals from entering the patent race.

In some cases, it is thus important for firms to stretch themselves to get into pole position: whether it be in terms of patents, copyright, real estate locations, getting the first pick in the labor market, choosing ideal strategic alliance partners, lead time benefits, and other first-mover benefits. This is analogous to Scott's decision to cover as much distance as possible each day to win the race to the South Pole, which leads to our Scott hypothesis:

The Scott hypothesis: the higher the volatility of growth paths, the higher the venture performance

However, there are also drawbacks to erratic growth. Lundmark et al. (2020) provide four reasons why volatility is detrimental to firm survival 
in the context of within-the-year revenue volatility. These four reasons are also germane to our multi-year firm growth context. First, volatility makes it harder to plan ahead. Firms may not have a clear vision of their demand or requirements for employees or production capacity, which could lead to costly mistakes when adjusting capacity in preparation for the near future (Bo, 2001). Firms may have to constantly revise their short-term projections and spend excessive time attempting to interpret flickering trends. Second, volatility adds psychological stress. Entrepreneurs and employees may be overworked some of the time, while finding themselves with nothing to do at other times, which could lead to frustration, lower job satisfaction, and perhaps lower quality work and less engagement with the venture (Pollard, 2001; Paulsen et al., 2005; Stephan, 2018). Third, volatility contributes to uncertainty. A classic tenet of financial economics is that higher risk must be compensated by higher returns for investors (Bloom, 2014). The venture may therefore suffer a risk premium in the eyes of banks, external investors, (potential) employees, strategic partners, and other stakeholders. Fourth, volatility raises average costs, for example, due to costs of warehousing or inventory control or worker overtime or other adjustment costs (e.g. Bo, 2001).

Another way of thinking about the costs of volatile growth is that the benefits of growth are non-linear: while moderate growth helps survival, nevertheless rapid growth can be detrimental to survival (Zhou \& Van der Zwan, 2019). Above a certain point, there is evidence that growth starts to reduce a firm's performance in terms of survival (Coad et al., 2020), and perhaps also other dimensions such as subsequent growth (Capasso et al., 2014). Daunfeldt and Halvarsson (2015) indicate that high-growth firms are usually "one-hit wonders" since they usually do not repeat their previous growth experience in subsequent periods. Rapid growth, above a certain point, seems subject to powerful forces of negative growth autocorrelation, according to which firms that grow very fast in 1 year are more likely to decline in the next (Capasso et al., 2014; Coad, 2007).

These empirical findings are consistent with suggestions that periods of rapid growth may bring about financial distress, if the firms disrupt the balance between costs and revenues (Brannback et al., 2014). Sudden bursts of growth can disrupt the balance between costs and revenues, they can increase the risk of exit, and they can lead to negative growth autocorrelation. While lumps and bumps in growth paths may be inevitable, nevertheless there may be leeway for ventures trying to manipulate its pace of growth — to "keep growth in check" (Bhide, 1992), to avoid excessive bursts where possible.

One reason for rapid growth being risky is due to difficulties in compressing the time needed for certain key tasks. While sometimes time can be saved by running tasks in parallel, this is not always possible. A popular anecdote is that 9 women cannot produce a baby in 1 month; instead it will take one woman 9 months. In the context of new ventures, the procedures of hiring and training new employees take a certain amount of time - and for good reason. If a firm seeks to compress the time taken for hiring and training, this could result in bad hires and a badly trained workforce. In other cases, trying to grow too fast could mean that quality is being sacrificed.

Therefore, having steady growth in each period could be preferable to combining dangerously fast growth in some years and low growth in others. Collins and Hansen (2011) have previously presented results from a number of case-studies that support their hypothesis that steady growth paths are better for long-run performance. This is analogous to Amundsen's decision to cover a fixed and equal distance to the South Pole each day, irrespective of weather conditions. Our Amundsen hypothesis therefore proposes:

The Amundsen hypothesis: the lower the volatility of growth paths, the higher the venture performance

\section{Method}

We test our hypotheses using firm-level data gathered from the Swedish Patent and Registration Office (PRV). All limited liability firms in Sweden are required by law to submit their annual reports to PRV, which means that we have detailed data on all Swedish limited liability firms over the period 1998-2009. The data include variables that can be found in the annual reports, e.g. sales, profits, number of employees, industry classification, and geographical location. In contrast to many other firm-level datasets, young firms are not under-represented, and information 
on registered start-up year is included (Coad et al., 2018).

We use annual sales as our firm growth indicator, and measure sales growth by calculating the logdifference of firm size (Tornqvist et al., 1985). We then investigate how growth paths are associated with firms' long-run performance by constructing an indicator of growth path volatility that measures the absolute area of growth rates that fluctuates around firms' average growth path. More specifically, we calculate:

Area $=\frac{1}{T} \sum_{t=0}^{T-1} \int_{t}^{t+1}|\ln S(x)-(a+b x)| d x$,

where $a=\ln S(0)$ is the $\log$ of firms size and the intercept of the average growth path and $b=T^{-1}(\ln S(T)-\ln S(0))$ is its slope. With discrete (annual) data on the growth, as captured by the change in $\ln S(x)$ from $t$ to $t+1, \ln S(x)$ can be replaced by a linear function, which allows for a closed form solution to the expression that can be implemented in statistical software such as Stata. Lastly, to facilitate the interpretation, we normalize Area to have a standard deviation of 1 in a given year $t$. A firm that experiences average growth in each year will have Area $=0$.

From the empirical implementation of the Area measure, we extract a complementary measure of the "erraticness" of a firm's growth path. It measures the number of "crossovers", i.e. how many times a firm's growth rate crosses over the average growth path. This measure presents one way to characterize firm's growth from $t=0$ to $t=T$ if it oscillates around the average growth path. The maximum number of crossovers are bound by $T-2$ when $T=4$, since by definition $\ln S(0)=a$ and $\ln S(T)=a+b T$. By using the Area measure and controlling for the number of crossovers, we get a measure of the growth volatility for firms given the number of times they have crossed the average growth path.

Our growth dispersion measure, Area, has several desirable properties. First, it takes value zero for the minimal deviation growth path, it is continuously valued, it is invariant to whether firm overshoots or undershoots on its growth trajectory (i.e. we use the modulus function to give overshooting or undershooting the same "importance" or magnitude), and relatively rapid decline (growth) contributes less to overall growth path volatility if the firm starts off above (below) the steady-growth benchmark.
Another desirable property of our growth dispersion measure is that we can relate it to the number of times the growth path crosses over the long-run average growth path, which makes it possible for us to distinguish between eight different types of growth paths. These growth paths and their definitions are highlighted in Table 1 below.

We use our new indicator of growth path variability to test if it is related to sales growth, profit growth and firm exit in the coming 3-year period after controlling for the number of crossovers of the long-run average growth path. We use the log difference (Tornqvist et al., 1985) to calculate sales growth, while the difference in net margins (expressed in percentage points) is used to measure profit growth. ${ }^{4}$ Finally, firm exit is measured by a binary variable that takes the value zero if the firm identification number continues to exist in the dataset and one if it ceases to exist. $^{5}$

Our dataset includes a register of the firms that took part of a merger or acquisition during the study period, which means that we are able to distinguish between organic and non-organic growth. As we are interested in the former, and because acquisitive growth may have different theoretical motivations and consequences than organic growth (Lockett, Wiklund, Davidsson, and Girma, 2011), we choose to exclude all firms that grow non-organically during the study period.

All estimations include dummies for 2-digit industries and controls for initial size (sales) and firms age, because a large body of previous work has confirmed that growth rates and exit rates depend on industry affiliation and also firm size and age. ${ }^{6}$ In order to control for non-linear effects, we also add quadratic terms for firm size and firm age. Finally, year-specific fixed effects are included to control for time-variant

\footnotetext{
${ }^{4}$ We focus not only on growth of sales, but also on growth of profits, as dependent variables, given that these two variables are alternative indicators of performance, that co-evolve in a complex relationship that may involve short-term tradeoffs (Cowling, 2004; Marris, 1964).

5 As is often done in the empirical literature, we group together voluntary liquidations with bankruptcies, because they are both instances of firm death (Coad, 2014).

${ }^{6}$ See, for example, Baù et al. (2019) for a recent concise discussion.
} 
Table 1 Eight growth paths based on the Area measure

\begin{tabular}{|c|c|}
\hline Graph type & Definition \\
\hline A: & $\begin{array}{l}\text { The growth path is over and never crossing the long-run average } \\
\text { growth path. }\end{array}$ \\
\hline B: & $\begin{array}{l}\text { The growth path is below and never crossing the long-run average } \\
\text { growth path. }\end{array}$ \\
\hline & $\begin{array}{l}\text { The growth path crosses the long-run average growth path } \\
\text { two times, with initial growth above the long-run average growth } \\
\text { path. }\end{array}$ \\
\hline & $\begin{array}{l}\text { The growth path crosses the long-run average growth path } \\
\text { two times, with initial growth below the long-run average growth } \\
\text { path. }\end{array}$ \\
\hline & $\begin{array}{l}\text { The growth path crosses the long-run average growth path one } \\
\text { time, with growth below the long-run average growth path in the } \\
\text { final year. }\end{array}$ \\
\hline & $\begin{array}{l}\text { The growth path crosses the long-run average growth path one } \\
\text { time, with growth above the long-run average growth path in the } \\
\text { final year. }\end{array}$ \\
\hline & $\begin{array}{l}\text { The growth path crosses the long-run average growth path one } \\
\text { time, with initial growth above the long-run average growth path. }\end{array}$ \\
\hline & $\begin{array}{l}\text { The growth path crosses the long-run average growth path one } \\
\text { time, with initial growth below the long-run average growth path. }\end{array}$ \\
\hline
\end{tabular}

Final size may be higher or lower than initial size. The number of growth types will increase with longer growth periods. For A and $\mathrm{B}$, Area is equal to the area of the trapezoid. For C and D, Area is equal to the area of the three triangles which have a side on the average growth line. For E-H, Area is equal to the area of the triangle and the trapezoid

exogenous shocks. Descriptive statistics for our sample are presented in Table 2 below.

The descriptive statistics show that the average firm has a sales growth rate that is -0.08 ( $\log$ points), showing that most firms in our sample have annual growth rates that are close to zero. We can also observe that firms on average have negative profit growth ( -1.66 percentage points) and that the share of firms that exit the market in each period is around 5\%. Our growth dispersion measure shows a lot of variation, and the descriptive statistics illustrate the fact that the number of crossovers of the average growth path is limited to 2 . The average growth path corresponds to the slope of the dashed line in each graph type in Table 1 and captures the average growth rate around which the Area measure is calculated.

Turning to our control variables, we observe that initial sales of the average firm amounts to 3.2 million SEK, $[3202=\exp (8.07154)]$. The average initial age for firms in the beginning of the growth period is 13.2 years. One attractive feature of our dataset is that we have access to information on firms' registered start year. We furthermore have no under-representation of young ventures, which otherwise is common (Bamford et al., 2004; Coad et al., 2018), and we

Table 2 Descriptive statistics, all firms

\begin{tabular}{lllc}
\hline Variable & $\mathrm{N}$ & Mean & Std. Dev \\
\hline Sales growth [log; $(\mathrm{t}: \mathrm{t}+3)]$ & 187,599 & -0.077 & 0.736 \\
Profit growth [ppt change; & 187,599 & -1.629 & 23.605 \\
$\quad(\mathrm{t}: \mathrm{t}+3)]$ & & & \\
Firm exit [Dummy; $(\mathrm{t}: \mathrm{t}+4)]$ & 218,261 & 0.048 & 0.213 \\
Area [sd(Area)=1] & 187,599 & 0.783 & 1.00 \\
Number of crossovers [\{0,1,2\}] & 187,599 & 0.584 & 0.671 \\
Average growth path [log; t-4:t] & 187,599 & 0.131 & 0.747 \\
Initial Size [log; $\mathrm{t}-4]$ & 187,599 & 8.072 & 1.513 \\
Initial age [t-4] & 187,599 & 13.275 & 12.748 \\
\hline
\end{tabular}


Table 3 Descriptive statistics (means) for eight growth path categories in Table 1

\begin{tabular}{|c|c|c|c|c|c|c|c|c|}
\hline & A & B & $\mathrm{C}$ & $\mathrm{D}$ & $\mathrm{E}$ & $\mathrm{F}$ & $\mathrm{G}$ & $\mathrm{H}$ \\
\hline Sales growth $[\log ;(t: t+3)]$ & -0.034 & -0.114 & -0.083 & -0.096 & -0.077 & -0.098 & -0.098 & -0.065 \\
\hline Profit growth [ppt change; $(\mathrm{t}: \mathrm{t}+3)]$ & 0.765 & -3.912 & -1.507 & -2.875 & -2.115 & -1.973 & -3.252 & -0.411 \\
\hline Firm exit [Dummy; $(\mathrm{t}: \mathrm{t}+4)]$ & 0.057 & 0.041 & 0.047 & 0.043 & 0.045 & 0.045 & 0.043 & 0.049 \\
\hline Area $[\mathrm{SD}($ Area $)=1]$ & 1.048 & 0.924 & 0.417 & 0.394 & 0.604 & 0.603 & 0.609 & 0.583 \\
\hline Crossovers & 0.000 & 0.000 & 2.000 & 2.000 & 1.000 & 1.000 & 1.000 & 1.000 \\
\hline Avg. growth path [log; (t-4:t)] & 0.182 & 0.104 & 0.124 & 0.100 & 0.047 & 0.155 & 0.058 & 0.188 \\
\hline Initial size [log; $t-4]$ & 7.952 & 8.267 & 7.925 & 8.050 & 8.030 & 8.091 & 8.093 & 8.042 \\
\hline Initial age [t-4] & 12.357 & 14.058 & 13.095 & 13.750 & 13.208 & 13.596 & 13.674 & 13.314 \\
\hline $\mathrm{N}$ & 53,556 & 43,898 & 9,353 & 10,083 & 17,520 & 18,011 & 15,714 & 19,464 \\
\hline
\end{tabular}

are thus able to look at growth paths of firms of all ages. As a check against "partial year effects" (Bernard et al., 2017) whereby the growth rates in the first year may be biased by having fewer than the usual 12 available months of sales in the first year, we repeat our analysis excluding all observations corresponding to a firm's first year of operations, obtaining similar results. More detailed definitions of the variables included in our analyses are provided in Table 5 in the Appendix.

Descriptive statistics for the eight different growth paths illustrated in Table 1 are presented in Table 3. A first observation is that the most populated growth path categories are the "trapezoids" A and $\mathrm{B}$, while the least populated are the "doublecrossover" paths $\mathrm{C}$ and $\mathrm{D}$. There are only small differences between the categories in terms of average sales growth, while profit growth is noticeably higher for group A, and noticeably lower for groups B, G, and D. Group A has the highest volatility according to the indicator "Area" and also a slightly higher exit rate.

\section{Results}

Our basic regression model investigates how growth path volatility during a 4-year period is related to sales growth, profit growth, and the likelihood of exit in the coming 3-year period. Our regression equation can be written as:

$$
\operatorname{Perf}_{i t}=a+\beta_{1} \text { Volatility }_{i t}+\beta_{2} X_{i t}+\varepsilon_{i t}
$$

where the dependent variable is an indicator of performance, Perf $_{i t} \in\left\{\right.$ Salesgrowth $_{i t}$, Profitgrowth $_{i t}$, Firmexit $\left._{i t}\right\}$ for firm $i$ in year $t$. Our main explanatory variables are the growth path volatility variables, and our control variables $\left(X_{i t}\right)$ include initial size, initial size squared, initial age, initial age squared, the interaction of initial size and initial age, and the average growth rate. Our regression equation is estimated via ordinary least squares (OLS), even in the case of firm exit. We apply an OLS linear probability model (OLS-LPM) for survival because the interpretation of marginal effects is more transparent in this case; see, e.g. Angrist \& Pischke, 2008. ${ }^{7}$

The results are presented in Table 4 and include year-specific and industry-specific (2-digit level) fixed effects. ${ }^{8}$ Multicollinearity was not considered to be a major risk. ${ }^{9}$ The $R^{2}$ statistic is low but in line

\footnotetext{
$\overline{7 \text { Considering }}$ that firm growth rates lack persistence and that the within-variation in firm growth rates is higher than the between-variation in growth rates (Geroski \& Gugler, 2004), we follow previous literature on firm growth (e.g. Coad, 2010) and do not include time-invariant firm-specific fixed effects in our regressions.

${ }^{8}$ For example, industry-specific fixed effects can alleviate possible issues of industry-specific degrees of volatility of annual growth rates. However, presumably the main type of industryspecific variations in demand occur at a seasonal frequency, not at the level of annual growth rates, and like the vast majority of firm growth research, we cannot control for within-the-year seasonal variations in demand. Another use of industry-specific fixed effects is to control for potential differences in the capital intensity of growth rates that may vary across industries.

9 A first reason for our present unconcern about multicollinearity is that we have a large number of observations (O'Brien, 2007). Furthermore, a correlation matrix (see table 6 in the appendix) allays fears about excessive pairwise correlations between variables. As an extra check, Online Appendix OSM3 verifies the stability of the coefficients across specifications as variable blocks are introduced stepwise.
} 
Table 4 Regression results. Relationship between growth path volatility $(t-4: t)$ and sales growth, profit growth, and firm exit over the subsequent period $(t: t+3)$

Robust standard errors in parentheses. Year-specific and industry-specific fixed effects are included in the regressions but not reported in detail. $* * * p<0.01$, $* * p<0.05, * p<0.1$

\begin{tabular}{llll}
\hline & $(1)$ & $(2)$ & $(3)$ \\
\hline Variables & Sales growth & Profit growth & Firm exit \\
Area & $0.025^{* * *}$ & $0.99^{* * *}$ & $0.0063^{* * *}$ \\
Crossover $=1$ & $(0.0040)$ & $(0.12)$ & -0.00061 \\
& $-0.0069^{*}$ & -0.19 & -0.00042 \\
Crossover=2 & $(0.0037)$ & $(0.12)$ & $(0.00099)$ \\
& -0.0075 & $-0.34^{*}$ & 0.0017 \\
Initial size & $(0.0058)$ & $(0.19)$ & $(0.0016)$ \\
& $-0.016^{* * *}$ & -0.0086 & $0.0029^{* * *}$ \\
Initial size sq & $(0.0017)$ & $(0.059)$ & $(0.00036)$ \\
& $0.0077^{* * *}$ & $0.12^{* * * *}$ & 0.000075 \\
Initial age & $(0.00063)$ & $(0.022)$ & $(0.00012)$ \\
& $-0.0035^{* * *}$ & $-0.026^{* * *}$ & $-0.00065^{* * *}$ \\
Initial age sq & $(0.00020)$ & $(0.0066)$ & $(0.000055)$ \\
Initial size-age interaction & $0.000062^{* * *}$ & $0.00059^{* * *}$ & $0.000011^{* * *}$ \\
& $(5.3 \mathrm{e}-06)$ & $(0.00021)$ & $(1.4 \mathrm{e}-06)$ \\
Average growth rate & -0.000033 & -0.0038 & $-0.000067^{* * *}$ \\
& $(0.000085)$ & $(0.0033)$ & $(0.000020)$ \\
Constant & $-0.094^{* * *}$ & $-3.15^{* * *}$ & $-0.0034^{* * *}$ \\
& $(0.0044)$ & $(0.14)$ & $(0.00067)$ \\
Observations & $0.16^{* * *}$ & $-2.23^{* * *}$ & -0.00031 \\
R-squared & $(0.017)$ & $(0.61)$ & $(0.0035)$ \\
\hline & 187,599 & 187,599 & 218,261 \\
& 0.022 & 0.015 & 0.015 \\
\hline
\end{tabular}

with the previous literature. ${ }^{10}$ Sector-disaggregated split-sample results are in Appendix OSM-4, and broadly confirm our main findings while also revealing sectoral heterogeneity. Appendix OSM-5 verifies the robustness of our results to alternative specifications regarding the profits variable.

We find that more volatile growth paths in the preceding 4-year period are positively associated with sales growth and profit growth in the subsequent periods. This is reflected by the coefficient estimates for the variable Area, which corresponds to the association of volatility with subsequent growth after having already controlled for Average growth rate. A one standard deviation increase of Area is associated with an increase in Sales growth of $2.5 \%$ (or $2.53=100 *(\exp (0.025)-1)$ to be exact $)$, which is a

\footnotetext{
10 See, for example, the survey of $R^{2}$ statistics obtained from growth rate regressions in Coad 2009, Table 7.1. Furthermore, we expect a low $R^{2}$ in our estimations, given that our sample covers a large number of small firms (whose growth rates are more erratic than for small samples of large firms).
}

large effect considering that Sales growth has an average of -0.08 and a standard deviation of 0.736 . For the other variables, respectively, a one standard deviation increase in Area is associated with an increase of Profit growth of 0.99 percentage points and an increase of Firm exit of 0.6. Volatility thus spurs subsequent growth. We thus find overall support for the Scott hypothesis, while the Amundsen hypothesis is not supported by our analysis. We also find that firms with more volatile growth paths are more likely to exit in the coming 3-year period. While volatile growth therefore boosts performance in terms of sales growth and profits growth, it hinders performance in terms of survival. Control variables generally display the expected signs. ${ }^{11}$

\footnotetext{
11 Note however that our estimates in Table 4 Column 3 suggest that higher initial size is positively associated with exit, which goes against many previous results. The usual interpretation of the size-exit relationship may not hold in Table 3 Column 3 because exit in $(t: t+3)$ is conditional upon surviving all of the growth path period $(\mathrm{t}-4: \mathrm{t})$, and this may select out small short-lived firms. In our data, the simple correlation between exit and once-lagged log size is indeed negative. Also,
} 
Fig. 1 Estimated marginal effects of volatility (i.e. the "Area" indicator) on sales growth in the coming 3-year period, for different parts of Average growth path

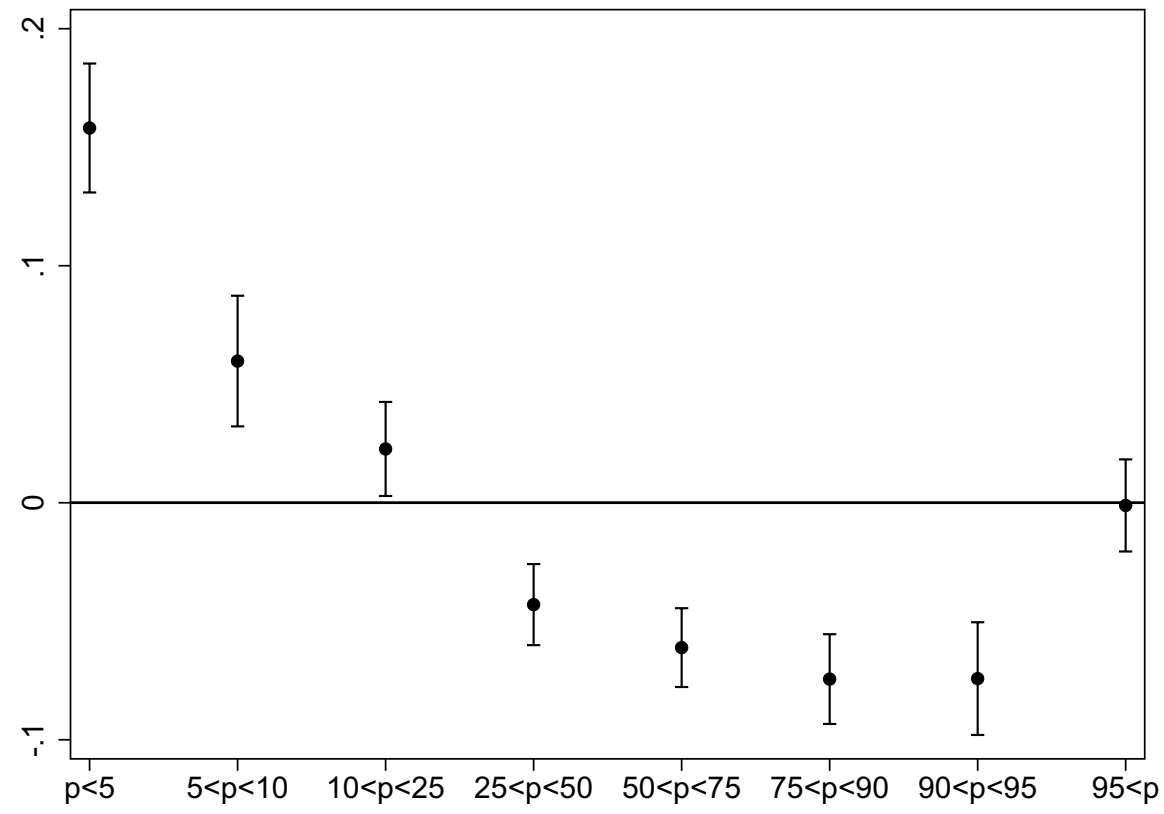

However, the results presented in Table 4 do not take into account that the growth path variability effect might differ across the growth rate distribution. Many firms are, for example, small and lack growth ambitions (Coad, 2009; Stam \& Wennberg, 2009; Wiklund \& Shepherd, 2003). These non-growing firms are characterized by low growth path variability and might therefore have a large impact on the estimated coefficients presented in Table 2. While entrepreneurship scholars often focus on the right tail of high-growth firms (HGFs), the OLS "conditional mean" effects shown in Table 4 might also be driven by firms in the left-hand side of the growth distribution, which are characterized by negative growth rates. Investigating heterogeneity across the growth rates distribution allows us to explore conjectures that high-potential firms are also high-variability firms (Wiklund \& Shepherd, 2011).

To take into account firm heterogeneity over the growth rate distribution, we continue by estimating the effect of growth path variability on our outcome

Footnote 11 (continued)

our regression results for this coefficient remain similar after a stepwise introduction of covariates. We therefore advise caution when interpreting the relationship between initial size and subsequent exit, and we do not suggest a naive interpretation that larger firms have higher exit rates. variables for different growth percentiles of the variable Average growth rate. Interaction effects between Area and the growth percentiles are here used to capture the effect of growth path variability for firms in different parts of the growth rate distribution. More specifically, we estimate the effect of growth-path variability for eight different growth classes (percentiles 0 to $5 ; 5$ to $10 ; 10$ to $25 ; 25$ to $50 ; 50$ to $75 ; 75$ to 90; 90 to 95; and 95 to 100). The marginal effects of growth path variability on our outcome variables are presented in Figs. 1-3 below, ${ }^{12}$ and the corresponding regression results can be found in Appendix OSM-1.

Figure 1 shows the effects of growth path variability on sales growth in the coming 3-year period for

\footnotetext{
12 The figures correspond to the relationship between growth path volatility $(t-4: t)$ over different percentile groups of the Average growth rate variable and sales growth, profit growth, and firm exit over the subsequent period $(t: t+3)$.

Essentially, this allows the "effect" of Area to vary, depending on where in the distribution of Average growth rate a firm is located. We include interaction effect between Area and a set of dummy variables that corresponds to the percentile groups of the Average growth rate variable. The point estimates, i.e. the marginal effects, is therefore given by $d y / d x=a+b(i) *$ $p(i) *$ (Average growth rate) where " $i$ " corresponds to the different percentile groups " $5<10, \ldots,>95$ ". The estimate for "a" corresponds to the result for $\mathrm{p}(<5)$, which is used as the reference group. The effects of subsequent groups such as $\mathrm{p}(5<10)$ is hence given by " $a+b(5<10)$ ".
} 
firms in different growth percentile classes. It is evident that growth path variability is positively related to sales growth for firms in the left-hand side of the growth rate distribution, i.e. for those with negative sales growth rates, while the opposite holds for firms that have positive growth or no growth at all. This means that, for the minority of firms with positive coefficients (at the left of Fig. 1), it seems that it is better to have a volatile decline (indicating perhaps some struggle and vitality, and attempts at innovation that were unlucky rather than non-existent) rather than a steady decline (indicating perhaps a passive resignation to deteriorating business conditions). In contrast, we find support for the Amundsen hypothesis for firms with positive growth rates, i.e. firms that are characterized by positive growth rates have higher sales growth in the coming 3-year period if their growth paths are less erratic.

The corresponding results for growth path variability on the change in profit growth are presented in Fig. 2. Firms with the most negative growth rates and high growth variability have more negative profit growth in coming periods compared to firms with lower growth variability in this growth percentile. This result turns insignificant for the second and third growth percentiles group and becomes negative for firms that are in the middle of the growth rate distribution that experience very low growth rates. The effect again turns insignificant for the seventh and eight growth percentiles, while the highgrowth firms experience a positive marginal effect of growth path variability on future profits. Highgrowth firms with more volatile growth paths are thus more likely to experience higher profit in the coming 3-year period compared to firms with less volatile growth paths.

The corresponding results for firm exit are presented in Fig. 3. Note that Fig. 3 appears "upsidedown" because we are measuring the likelihood of firm exit, which means that "success" (i.e. survival) is reverse-coded. The results show that growth path volatility is negatively related to firm exit for firms in the $5<\mathrm{p}<10$ growth percentile, which consists of firms that are characterized by negative sales growth rates. The effect turns positive for firms that are above the $25 \%$ percentile, showing that higher growth path volatility is associated with an increased risk of exit (i.e. less chance of survival) for firms with marginal or positive sales growth. Volatility is thus harmful for most firms, including all firms that experienced positive growth. A silver lining could be that volatility is positively associated with survival for fast-declining firms (with statistically significant results for the $5<\mathrm{p}<10$ class), if, for example, it is better to decline with some struggle and interruption rather than having a smooth deterioration.
Fig. 2 Estimated marginal effects of volatility (i.e. the "Area" indicator) on profit growth in the coming 3-year period, for different parts of Average growth path

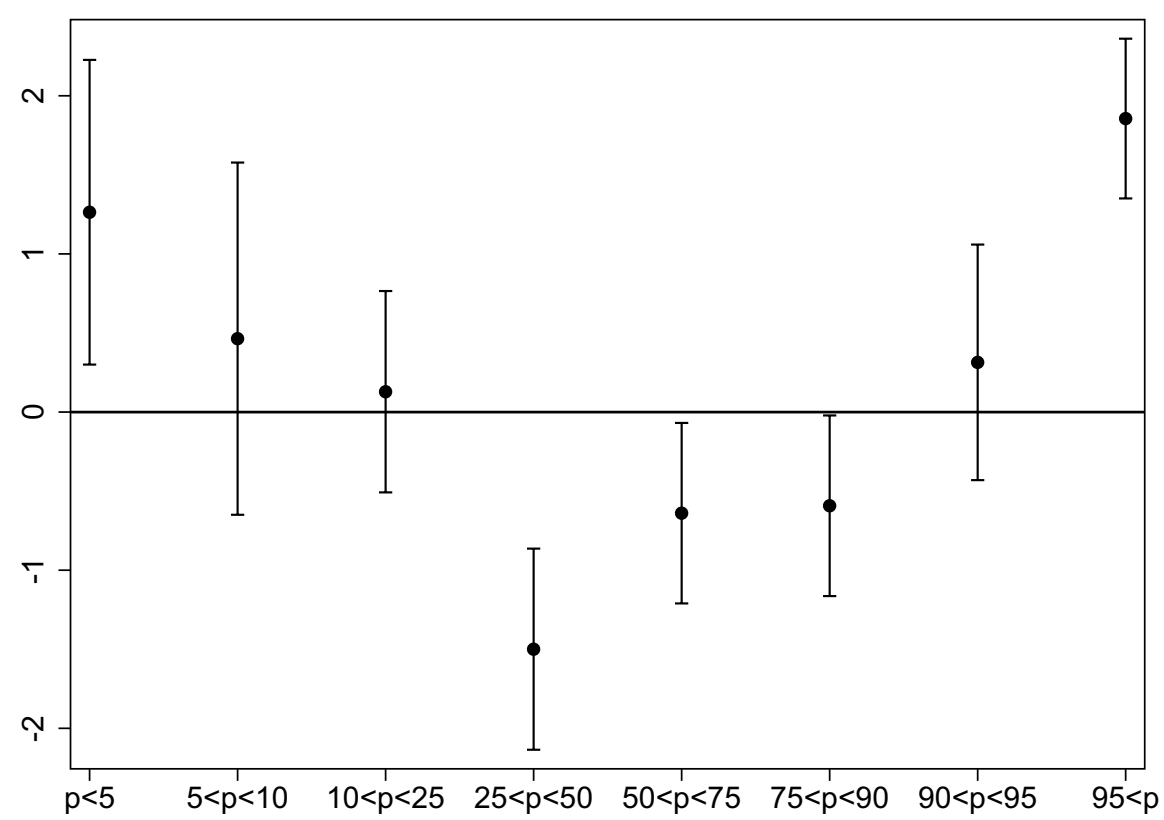


Fig. 3 Estimated marginal effects of volatility (i.e. the "Area" indicator) on firm exit in the coming 3-year period, for different parts of Average growth path

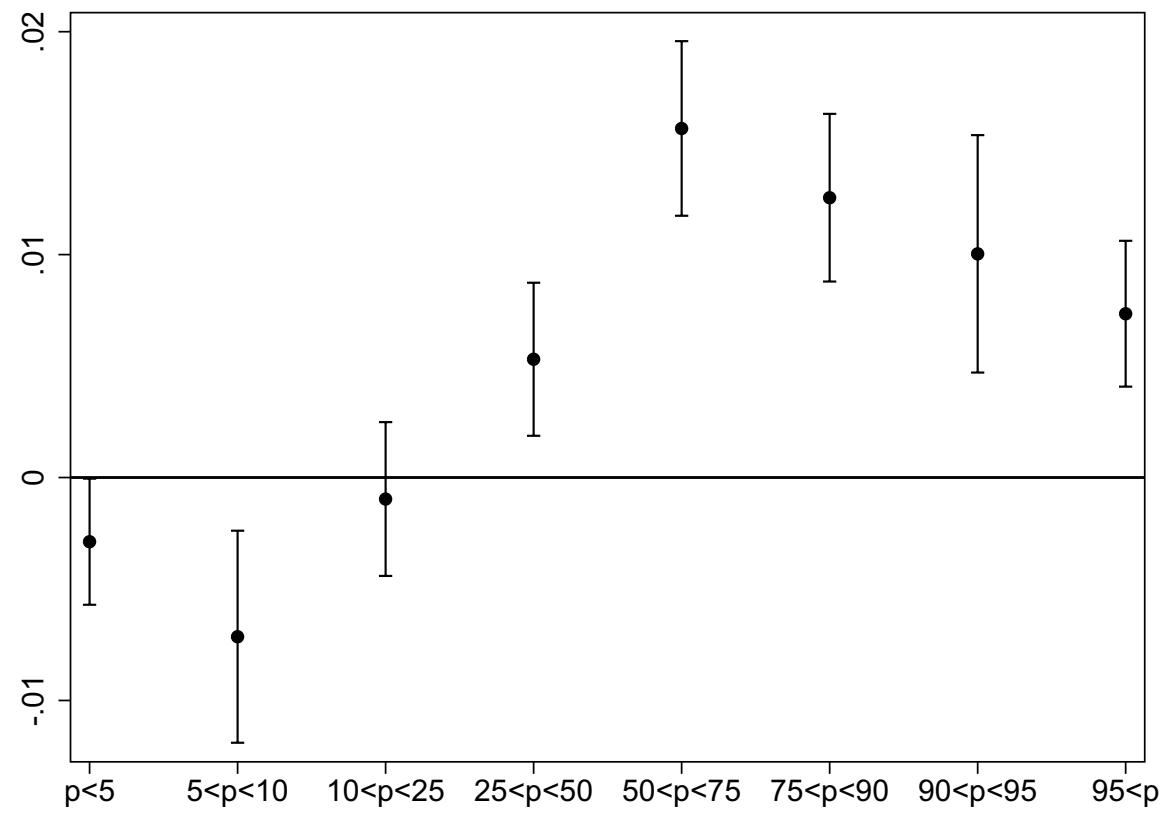

Next, we distinguish between the eight different growth path types that are displayed in Table 1 . We want to investigate if these growth path types are related to sales growth, growth in profitability, and firm exit in the coming 3-year period. Marginal effects are presented in Figs. 4-6 below together with their $95 \%$ confidence intervals. The corresponding regression results are presented in Appendix OSM-2.
Figure 4 shows a distinct pattern, namely that those firms that are characterized by more years with sales growth that is above rather than below their average growth rate (i.e. A, C, E, and $\mathrm{H}$ in Table 1) have higher sales growth in the coming 3 -year period. This is consistent with the conjecture that a sudden sharp decline in 1 year is not too unusual and does not rule out above-average growth in subsequent years.
Fig. 4 Estimated marginal effects of Area on sales growth in the coming 3-year period by growth path categories $(\mathrm{A}-\mathrm{H})$

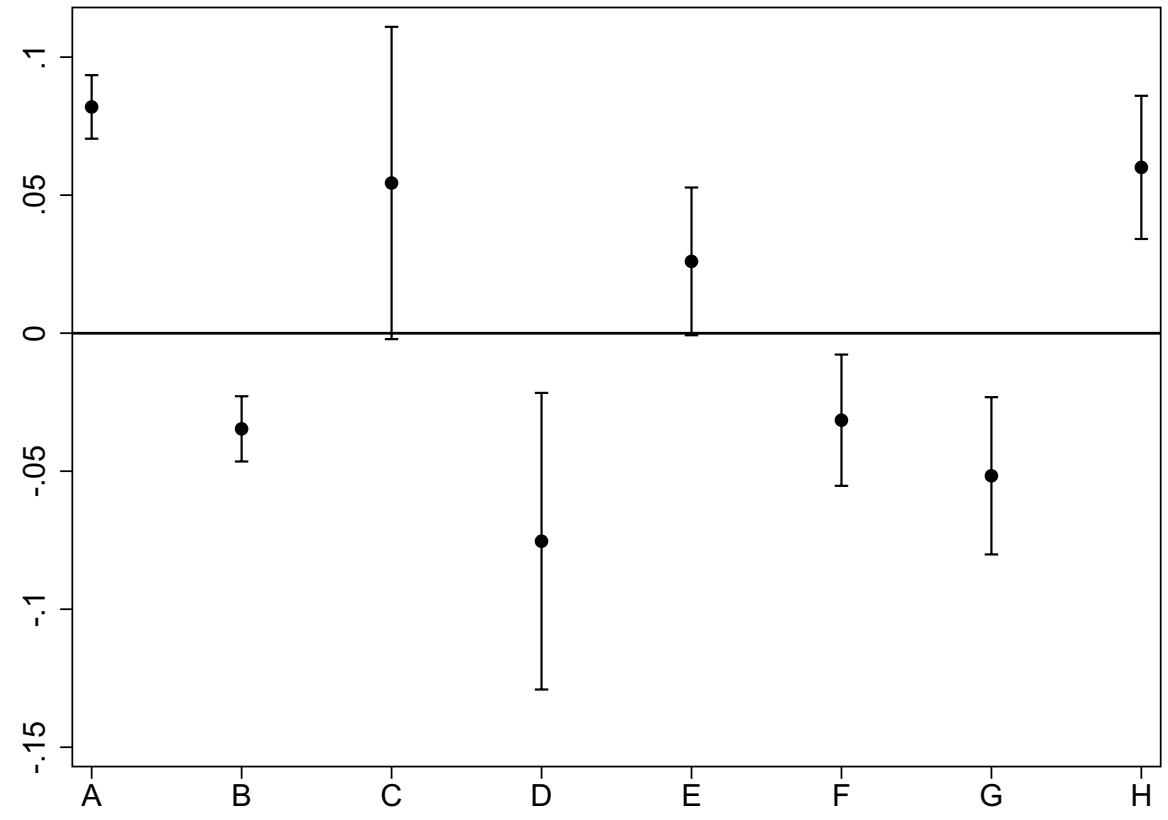


Fig. 5 Estimated marginal effects of Area on profit difference in the coming 3-year period by growth path categories $(\mathrm{A}-\mathrm{H})$

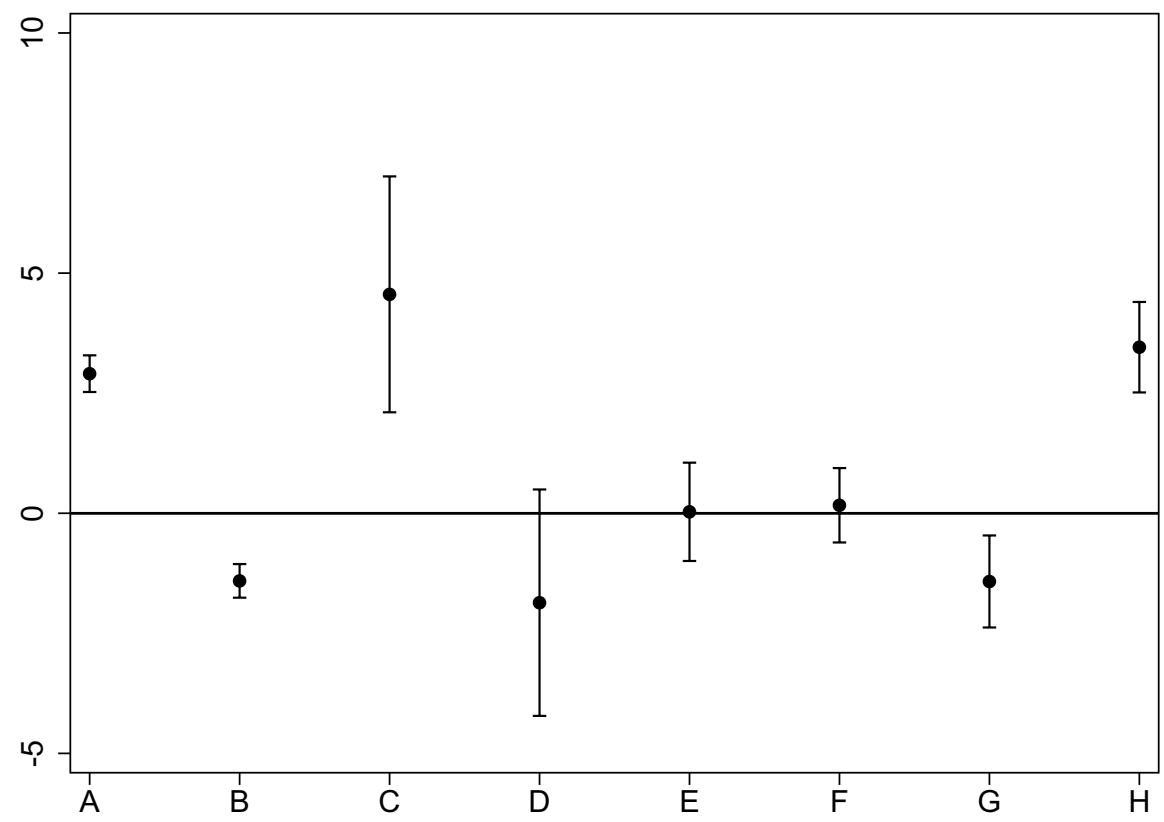

We find broadly similar results for profit growth in Fig. 5, i.e. firms with a yearly sales growth rate that exceeds their average growth path during at least two periods are more likely to be characterized by higher profit growth in the coming 3-year period. ${ }^{13}$ Firms that have a sales growth that is below their average growth path until the last year (graph type B) is also more likely to be characterized by negative profit growth in the coming 3-year period.

Finally, the results for firm exit (Fig. 6) show varying exit rates across growth path categories. In most cases, we find no significantly differences in firm exit for firms with different growth types because the confidence intervals overlap. However, firms with two crossings that start with below-average sales growth (D) have a significantly higher risk of exit compared to firms that have no crossings of their growth path.

We also used the absolute min-max growth difference $(A M M)$ and the standard deviation $(S D)$ to investigate if they are related to sales growth, profit growth, and likelihood of exit in the coming 3-year period. Our indicators of growth path volatility are generally highly positively correlated (see Table 5),

\footnotetext{
13 This is no longer observed for category E, however, as we move from Fig. 4 to Fig. 5.
}

and all main results remain qualitatively similar when using these growth dispersion measures instead. ${ }^{14}$ Note, however, that these alternative growth dispersion measures cannot be used to classify firms into different growth types (Table 1). Hence, these alternative measures only capture the volatility aspect and not how growth paths more generally are related to firm performance.

\section{Discussion and implications}

A small number of high-growth firms have been observed to be instrumental for job creation, and interest in rapid growth firms has therefore grown rapidly in recent years (Davidsson et al., 2009; Henrekson \& Johansson, 2010, Coad et al., 2014). However, firms that are growing fast also seem unable to repeat their growth experience in subsequent periods (Capasso et al., 2014; Daunfeldt \& Halvarsson, 2015).

High-growth firms are typically characterized by high volatility in their growth rates. Some economic models suggest that their inability to have more persistent growth might be related to the inherent volatility of the firm growth process (Bottazzi and Secchi,

\footnotetext{
14 These results are omitted in order to save space, but are available from the authors upon request.
} 
Fig. 6 Estimated marginal effects of Area on firm exit in the coming 3-year period by growth path categories $(\mathrm{A}-\mathrm{H})$

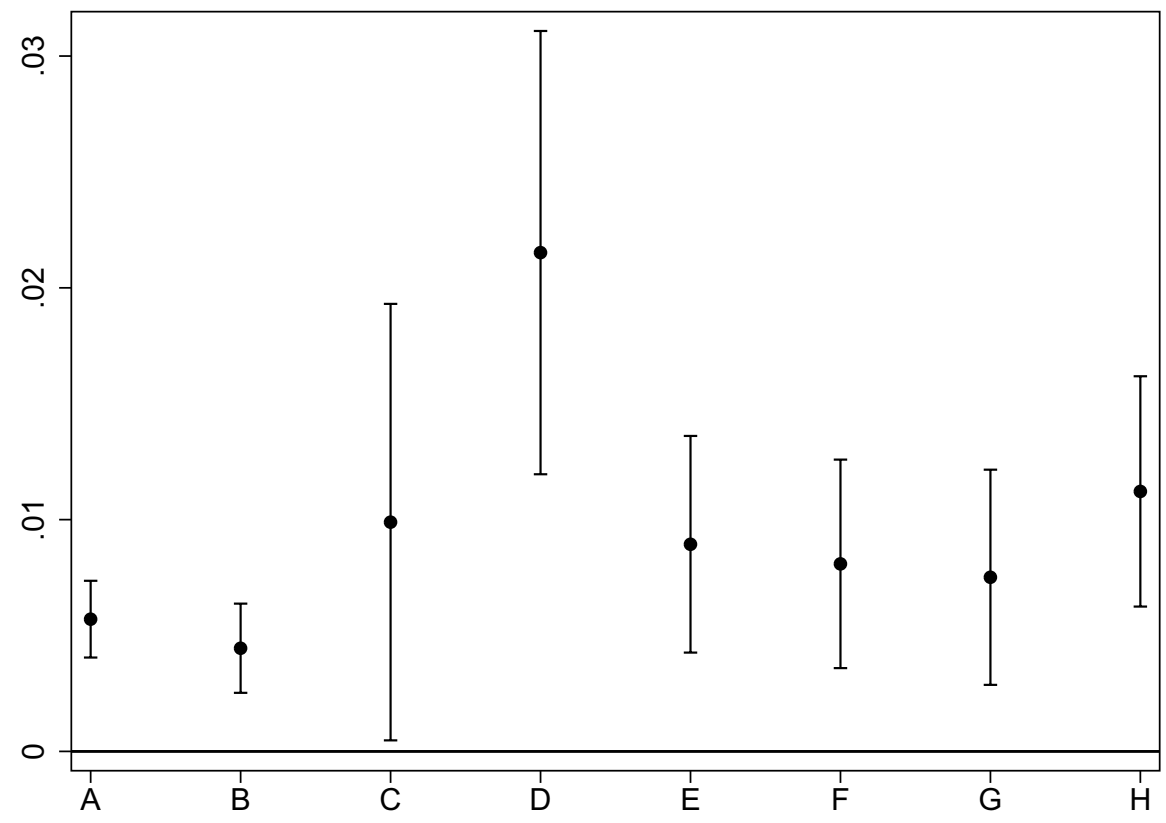

2006; Coad \& Planck, 2012), which links back to the Amundsen versus Scott dilemma. Amundsen's team paced themselves: they went similar distances, irrespective of how favorable the weather conditions were, and they won the race to the South Pole. Translated into our context, we ask: Is it better to have steady growth or to grow as fast as possible in each period?

We make a number of contributions to advance entrepreneurship thinking in this area. We begin by drawing together theoretical insights to reason why, on the one hand, growth path variability might lead to unfavorable outcomes, while on the other hand, growth path variability might be positively related to how firms perform in the coming period. Overall, theory provides no clear answer regarding how growth path variability relates to firm performance. Our empirical investigation began with the development of a toolkit of novel growth path variability measures (growth path types, area between growth path and average growth, number of crossovers, min-max difference, and standard deviation) that made it possible for us to quantify growth path variability and to classify how firms grow in relation to their long-run average growth path. This enabled our large-sample investigation of whether firms' growth paths were related to their subsequent performance, in terms of sales growth, profit growth, and likelihood of exit in coming periods. Our aim was to investigate if the Amundsen hypothesis holds, i.e. if firms with more stable growth paths are characterized by better longrun performance than firms who are characterized by more volatile growth paths.

Our baseline regressions (Table 4) showed that growth volatility (measured using "Area") was positively associated with growth of sales and profits. However, this relationship seems conditional on the firm's position on the growth rate distribution. We found that more volatile growth paths affected subsequent sales growth negatively for the fastest growing firms. Firms with relatively high growth rates (as reflected by a steep average growth path) and a smooth growth path are thus expected to see higher sales growth in coming periods compared to similar firms with more erratic growth paths. Consistency in growth is an advantage for the subsequent sales growth of firms that have positive growth overall. More stable growth paths are also generally found to be associated with a lower risk of exiting the market, while profit growth in general seems to be less clearly influenced by firms' growth paths. The Amundsen hypothesis therefore receives nuanced support in our analysis, being more relevant for firms with non-negative growth rates (Fig. 5).

Our results do not suggest unequivocally that "volatility is bad", for two reasons. First, although 
steadiness in growth is beneficial for firms having positive growth overall, steady decline is worse than erratic decline (for firms having negative growth overall). Second, growth path volatility is a "risky gamble" in the sense that it predicts higher growth rates of sales and profits, while it also predicts higher exit rates. A possible mechanism for this latter finding could be that high-opportunity-cost entrepreneurs with attractive outside options would rather take all risks in the pursuit of success rather than linger in a business with modest prospects (Arora \& Nandkumar, 2011). Thus, ambitious entrepreneurs could be impatient to grow fast and pursue all available growth opportunities (in line with Scott's strategy) despite the exit risk of such volatile growth. However, given that our estimates do not emerge from a causal econometric framework, caution is needed when discussing the mechanisms that may be driving our results.

Our analysis yields a number of implications for various stakeholders (e.g. entrepreneurs, employees, banks, investors, policymakers, academics). The traditional wisdom is that growth is good for firms and their stakeholders. However, we observe that growth path volatility is overall negatively associated with survival. Possible mechanisms are that growth path volatility increases uncertainty, which leads to worse decision-making, psychological stress, risk premia for stakeholders, and higher adjustment costs, thereby leading to exit (Lundmark et al., 2020). An implication is that entrepreneurs with strong preferences for continuation (e.g. entrepreneurs keen to keep a family tradition alive, or entrepreneurs with few outside options) may prefer to pursue steady growth rather than taking a more frenzied approach to the pursuit of growth opportunities (Arora \& Nandkumar, 2011). Other stakeholders (investors, employees) may also be cautious in engaging with firms that have volatile growth paths. Analysis of firms at the lower growth quantiles, however, suggests that a volatile path of decline is preferable to a steady decline, in the sense that a volatile path of decline is more likely to be followed by subsequent growth of sales and profits. In the case of firms at the extreme upper end of the growth distribution (i.e. the fastest growing firms), growth path volatility is positively linked to profits growth, suggesting that ambitious entrepreneurs may pursue higher profits despite facing higher exit rates (Arora \& Nandkumar, 2011).
Our study can be seen as a first attempt to investigate an unexplored dimension in the emerging entrepreneurship field on growth modes by quantifying the volatility of growth paths and by evaluating how such volatility relates to subsequent performance. However, a limitation of our research is that the results relate to conditional associations rather than causal effects. Future work could potentially build on our present contribution to better pin down the causality of the relationship, e.g. by finding a way to rule out the potential role of unobserved confounders to better identify the specific effect of growth path volatility on firm performance. For example, if for each growing firm with a volatile growth path, there is a suitable counterfactual "twin" for how that same firm would have performed had it chosen to pursue a less volatile growth path.

Another challenging area for future work is to investigate more closely if there is an optimal amount of volatility. While growth path volatility is harmful on average, there are theoretical reasons to suspect that some volatility is necessary and perhaps even beneficial in small amounts. Drawing on our analysis of effects along the distribution, the optimal amount of volatility may also depend on the overall total growth of the venture. Future work could also investigate whether different degrees of volatility in growth paths are linked to the number of customers a firm has (e.g. if a firm with a single stable source of demand enjoys stable growth, while also potentially being vulnerable to over-reliance on a single customer), as well as the degree of capital intensity (as opposed to labor intensity) of growth. Future research would also be valuable, more generally, to explore whether our results are generalizable to other samples from other time periods and countries.

In general, we believe that entrepreneurship scholars should focus their attention more on how firms grow, instead of focusing merely on how much firms grow (McKelvie \& Wiklund, 2010). Our toolkit for characterizing and quantifying growth path volatility will hopefully provide an impetus to research in this emerging field. 


\section{Appendix 1 details on the sample and variables}

We also test if our results are robust to commonly used growth dispersion measures, such as the absolute min-max growth difference $(A M M)$. The $A M M$ measure is calculated by first ranking a firm's growth rates in order of size and then calculating the absolute difference between the firm's largest growth rate and the smallest growth rate. More formally, if $\left|s^{\max }\right|=\max \left(\left|\ln \frac{S(t+1)}{S(t)}\right|\right)_{t=0}^{T}$ and $\left|s^{\min }\right|=\min \left(\left|\ln \frac{S(t+1)}{S(t)}\right|\right)_{t=0}^{T}$ corresponds to the largest and smallest absolute growth rates over the sequence of growth rates, the $A M M$ measure can be defined as:

$A M M=\left|s^{\max }-s^{\min }\right|$
Finally, in order to compare our results with a traditional volatility measure, we have also done all estimations using the standard deviation $(S D)$ as our growth dispersion measure.

All growth dispersion measures that are used in the paper are normalized to have mean zero, and a standard deviation of one. To calculate Area and AMM, we use consecutive periods, each with $T=4$. The outcome measures, we consider is the future growth rate of $\ln \frac{S(T+k)}{S(T)}$ with $k=1,2$ and 3 .

The correlation between our new indicator of growth dispersion and the more traditional ones are presented in Table 1

Our main results remain qualitatively similar when using the alternative growth dispersion measures. Note, however, that these alternative growth dispersion measures cannot be used to categorize firms into different growth types (see Table 5).

Table 5 Correlation matrix

\begin{tabular}{lllllllllllll}
\hline Firm exit & 1.00 & & & & & & & & & \\
Sales growth & -0.02 & 1.00 & & & & & & & & \\
Profit growth & 0.00 & 0.36 & 1.00 & & & & & & & \\
Area & 0.04 & 0.04 & 0.04 & 1.00 & & & & & & \\
Crossover & -0.01 & -0.01 & -0.01 & -0.22 & 1.00 & & & & & \\
SD & 0.03 & 0.03 & 0.03 & 0.90 & 0.00 & 1.00 & & & & \\
AMM & 0.04 & 0.04 & 0.04 & 0.89 & -0.03 & 0.95 & 1.00 & & & \\
Initial size & 0.02 & -0.02 & 0.01 & -0.23 & -0.02 & -0.25 & -0.24 & 1.00 & & \\
Initial age & -0.02 & -0.02 & 0.00 & -0.09 & 0.01 & -0.09 & -0.09 & 0.26 & 1.00 & \\
(Initial age)*(Initial size) & 0.00 & 0.00 & 0.00 & -0.01 & -0.01 & -0.02 & -0.01 & 0.25 & 0.45 & 1.00 \\
Average growth path & -0.02 & -0.08 & -0.10 & 0.00 & -0.02 & -0.01 & 0.01 & -0.14 & -0.07 & 0.02 \\
\hline
\end{tabular}

Table 6 Definitions of variables

\begin{tabular}{|c|c|}
\hline Variable & Definition \\
\hline Sales growth & Sales growth is defined by $\log [\operatorname{Sales}(\mathrm{t}+3) / \mathrm{Sales}(\mathrm{t})]$ where sales is the deflated annual sales in time period $t$ \\
\hline Profit growth & $\begin{array}{l}\text { Profit growth is here given by Profit }(\mathrm{t}+3) \text {-Profit }(\mathrm{t}) \text {, where profit is the percentage net margin in time period } t \text {. } \\
\text { Profit growth is hence expressed in terms of percentage points (ppt.) }\end{array}$ \\
\hline Firm exit & $\begin{array}{l}\text { Dummy variable that takes the value of } 1 \text { if a firm has exited the panel between the years } t \text { and } t+4 \text {, and } 0 \\
\text { otherwise. Note than firms that exit within the period }[t: t+3] \text { do not have sales or profits in the period } t+3 \\
\text { and therefore are not part of the analysis of sales and profit growth }\end{array}$ \\
\hline Area & $\begin{array}{l}\text { The definition of Area is given in Eq. (1). It gives a variability measure of } \log [\operatorname{Sales}(\mathrm{t})] \text { over the period } t-4 \text { to } \\
t \text {. To easy interpretation it has been normalized to have standard deviation equal to } 1 \text { in a given year }\end{array}$ \\
\hline Number of crossovers & $\begin{array}{l}\text { The number of crossovers gives the number of times the growth path crosses over the average growth path } \\
\text { (dashed line in Fig. 1) in the period } t-4 \text { to } t \text {. It takes the values } 0,1 \text {, and } 2\end{array}$ \\
\hline Average growth path & $\begin{array}{l}\text { Average growth path gives the average growth rate in terms of Sales for the period t- } 4 \text { to } t \text { and corresponds to } \\
\text { the slope of the dashed line in Fig. } 1 \text {. Note that the slope is equal to } 0 \text { in Fig. } 1 \text { for simplicity }\end{array}$ \\
\hline Initial Size & Initial size is the log of Sales at the time $t-4$ \\
\hline Initial age & Initial age is the year since foundation at the time $\mathrm{t}-4$ \\
\hline
\end{tabular}




\section{References}

Acs Z., Parsons W., Tracy S., (2008). High impact firms: Gazelles revisited. SBA working paper No. 328, June.

Angrist, J. D., \& Pischke, J.-S. (2008). Mostly harmless econometrics: An empiricist's companion. Princeton University Press.

Arora, A., \& Nandkumar, A. (2011). Cash-out or flameout! Opportunity cost and entrepreneurial strategy: Theory, and evidence from the information security industry. Management Science, 57(10), 1844-1860.

Bamford, C. E., Dean, T. J., \& Douglas, T. J. (2004). The temporal nature of growth determinants in new bank foundings: Implications for new venture research design. Journal of Business Venturing, 19, 899-919.

Baù, M., Chirico, F., Pittino, D., Backman, M., \& Klaesson, J. (2019). Roots to grow: Family firms and local embeddedness in rural and urban contexts. Entrepreneurship Theory and Practice, 43(2), 360-385.

Bernard, A. B., Boler, E. A., Massari, R., Reyes, J. D., \& Taglioni, D. (2017). Exporter dynamics and partial-year effects. American Economic Review, 107(10), 3211-3228.

Bhide, A. (1992). Bootstrap finance: The art of start-ups. Harvard Business Review, 70(6), 109-117.

Bottazzi, G., \& Secchi, A. (2006). Explaining the distribution of firm growth rates. Rand Journal of Economics, 37(2), 235-256.

Brännback, M., Carsrud, A. L., Kiviluoto, N. (2014). Understanding the myth of high growth firms: The theory of the greater fool. Springer Science \& Business Media. Springer

Bloom, N. (2014). Fluctuations in uncertainty. Journal of Economic Perspectives, 28(2), 153-176.

Bo, H. (2001). Volatility of sales, expectation errors, and inventory investment: Firm level evidence. International Journal of Production Economics, 72(3), 273-283.

Brenner, T., \& Schimke, A. (2015). Growth development paths of firms - A study of smaller businesses. Journal of Small Business Management, 53(2), 539-557.

Brynjolfsson, E., Rock, D., \& Syverson, C. (2021). The productivity J-curve: How intangibles complement general purpose technologies. American Economic Journal: Macroeconomics, 13(1), 333-372.

Capasso, M., Cefis, E., \& Frenken, K. (2014). On the existence of persistently outperforming firms. Industrial and Corporate Change, 23(4), 997-1036.

Carow, K., Heron, R., \& Saxton, T. (2004). Do early birds get the returns? An empirical investigation of early-mover advantages in acquisitions. Strategic Management Journal, 25(6), 563-585.

Coad, A. (2007). A closer look at serial growth rate correlation. Review of Industrial Organization, 31, 69-82.

Coad, A. (2009). The growth of firms: A survey of theories and empirical evidence. Edward Elgar Publishing.

Coad, A. (2010). Exploring the processes of firm growth: Evidence from a vector autoregression. Industrial and Corporate Change, 19(6), 1677-1703.

Coad, A., Daunfeldt, S. O., Hölzl, W., Johansson, D., \& Nightingale, P. (2014). High-growth firms: Introduction to the special section. Industrial and Corporate Change, 23(1), 91-112.
Coad, A., Daunfeldt, S. O., \& Halvarsson, D. (2018). Bursting into life: Firm growth and growth persistence by age. Small Business Economics, 50(1), 55-75.

Coad, A., Frankish, J., Roberts, R., \& Storey, D. (2013). Growth paths and survival chances: An application of Gambler's ruin theory. Journal of Business Venturing, 28, 615-632.

Coad, A., Frankish, J. S., Roberts, R. G., \& Storey, D. J. (2015). Are firm growth paths random? A reply to "Firm growth and the illusion of randomness." Journal of Business Venturing Insights, 3, 5-8.

Coad, A., Frankish, J. S., \& Storey, D. J. (2020). Too fast to live? Effects of growth on survival across the growth distribution. Journal of Small Business Management, 58(3), 544-571. https://doi.org/10.1080/00472778.2019.16622 65

Coad, A., \& Planck, M. (2012). Firms as bundles of discrete resources - Towards an explanation of the exponential distribution of firm growth rates. Eastern Economic Journal, 38, 189-209.

Collins, J., \& Hansen, M. T. (2011). Great by choice: Uncertainty, chaos and luck-why some thrive despite them all. Random House.

Cowling, M. (2004). The growth-profit nexus. Small Business Economics, 22(1), 1-9.

Cowling, M., \& Liu, W. (2011). ASBS barometer report on business growth, access to finance, and performance outcomes in the recession. Department for Business, Innovation and Skills.

Cowling, M., Liu, W., Yue, W., \& Do, H. (2019). Market consolidation, market growth, or new market development? Owner, firm, and competitive determinants.International Review of Entrepreneurship, 17(1)

Cowling, M., \& Nadeem, S. P. (2020). Entrepreneurial firms: With whom do they compete, and where? Review of Industrial Organization, 57(3), 559-577.

Cruz, M., Bussolo, M., \& Iacovone, L. (2018). Organizing knowledge to compete: Impacts of capacity building programs on firm organization. Journal of International Economics, 111, 1-20.

Davidsson, P., Steffens, P., \& Fitzsimmons, J. (2009). Growing profitable or growing from profits: Putting the horse in front of the cart? Journal of Business Venturing, 24(4), 388-406.

Daunfeldt, S. O., \& Halvarsson, D. (2015). Are high-growth firms one-hit wonders? Evidence from Sweden. Small Business Economics, 44(2), 361-383.

Delmar, F., Davidsson, P., \& Gartner, W. B. (2003). Arriving at the high-growth firm. Journal of Business Venturing, 18, 189-216.

Derbyshire, J., \& Garnsey, E. (2014). Firm growth and the illusion of randomness. Journal of Business Venturing Insights, 1, 8-11.

Doms, M., \& Dunne, T. (1998). Capital adjustment patterns in manufacturing plants. Review of Economic Dynamics, 1(2), 409-429.

Garnsey, E., \& Heffernan, P. (2005). Growth setbacks in new firms. Futures, 37(7), 675-697.

Garnsey, E., Stam, E., \& Heffernan, P. (2006). New firm growth: Exploring processes and paths. Industry and Innovation, 13(1), 1-20. 
Geroski, P., \& Gugler, K. (2004). Corporate growth convergence in Europe. Oxford Economic Papers, 56, 597-620.

Gilbert, R. J., Newbery, D. M. (1982). Preemptive patenting and the persistence of monopoly. The American Economic Review, 514-526.

Hamermesh, D. S., \& Pfann, G. A. (1996). Adjustment costs in factor demand. Journal of Economic Literature, 34(3), 1264-1292.

Hannan, M. T., \& Freeman, J. (1977). The population ecology of organizations. American Journal of Sociology, 82(5), 929-964.

Henrekson, M., \& Johansson, D. (2010). Gazelles as job creators: A survey and interpretation of the evidence. Small Business Economics, 35(2), 227-244.

Lieberman, M. B., \& Montgomery, D. B. (1988). First-mover advantages. Strategic Management Journal, 9(S1), 41-58.

Lockett, A., Wiklund, J., Davidsson, P., \& Girma, S. (2011). Organic and acquisitive growth: re-examining, testing and extending Penrose's growth theory. Journal of Management Studies, 48(1), 48-74.

Lundmark E., Coad A., Frankish J.S., Storey D.J. (2020). The liability of volatility and how it changes over time among new ventures. Entrepreneurship Theory and Practice, in press.

Marris, R. (1964). The Economic Theory of Managerial Capitalism. Macmillan.

McKelvie, A., \& Wiklund, J. (2010). Advancing firm growth research: A focus on growth mode instead of growth rate. Entrepreneurship Theory and Practice, 34(2), 261-288.

McMahon, R. G. P. (2001). Deriving an empirical development taxonomy for manufacturing SMEs using data from Australia's Business Longitudinal Survey. Small Business Economics, 17, 197-212.

O'Brien, R. M. (2007). A caution regarding rules of thumb for variance inflation factors. Quality \& Quantity, 41(5), 673-690.

Paulsen, N., Callan, V. J., Grice, T. A., Rooney, D., Gallois, C., Jones, E., Jimmieson, N. L., \& Bordia, P. (2005). Job uncertainty and personal control during downsizing: A comparison of survivors and victims. Human Relations, 58(4), 463-496.

Penrose, E. T. (1959). The Theory of the Growth of the Firm. Oxford, UK: Basil Blackwell.

Pollard, T. M. (2001). Changes in mental well-being, blood pressure and total cholesterol levels during workplace reorganization: The impact of uncertainty. Work \& Stress, 15(1), 14-28.

Spence, A. M. (1981). The learning curve and competition. The Bell Journal of Economics, 49-70.

Stam, E., \& Wennberg, K. (2009). The roles of R\&D in new firm growth. Small Business Economics, 33, 77-89.

Stephan, U. (2018). Entrepreneurs' mental health and wellbeing: A review and research agenda. Academy of Management Perspectives, 32(3), 290-322.

Törnqvist, L., Vartia, P., \& Vartia, Y. O. (1985). How should relative changes be measured? The American Statistician, 39(1), 43-46.

Wernerfelt, B. (1986). A special case of dynamic pricing policy. Management Science, 32(12), 1562-1566.

Wernerfelt, B. (1988). General equilibrium with real time search in labor and product markets. Journal of Political Economy, 96(4), 821-831.

Wiklund, J., \& Shepherd, D. (2003). Aspiring for, and achieving growth: The moderating role of resources and opportunities. Journal of Management Studies, 40(8), 1919-1941.

Wiklund, J., \& Shepherd, D. A. (2011). Where to from here? EO-as-experimentation, failure, and distribution of outcomes. Entrepreneurship Theory and Practice, 35(5), 925-946.

Zhou, H., \& van der Zwan, P. (2019). Is there a risk of growing fast? The relationship between organic employment growth and firm exit. Industrial and Corporate Change, forthcoming. https://doi.org/10.1093/icc/dtz006

Publisher's note Springer Nature remains neutral with regard to jurisdictional claims in published maps and institutional affiliations. 